\title{
CONSIDERAÇÕES FENOMENOLÓGICAS SOBRE A VIVÊNCIA DA SUPERAÇÃO NO TATAME
}

\author{
CANTERI, Bianca Teixeira ${ }^{1}$; ESPINHA, Tatiana Gomez ${ }^{2}$.
}

\section{RESUMO}

O presente artigo apresenta uma pesquisa realizada em 2016 que teve como objetivo compreender a experiência da superação de atletas profissionais e amadores a partir de uma perspectiva fenomenológica. As entrevistas e análises realizadas com atletas do Jiu Jitsu ajudaram a compreender o fenômeno da superação. A superação relacionou-se a uma experiência positiva, que proporciona ganhos e se estende para fora do contexto esportivo, e que tendo o limite como característica essencial atribui valor à prática esportiva em si. O atleta que passa a reconhecer seus limites ao ser desafiado relaciona-se com aspectos existenciais da vida estudados pela Psicologia de referencial fenomenológico.

Palavras-chave: Superação. Psicologia. Fenomenologia.

\begin{abstract}
This article presents a research done in 2016 that had as purpose to comprehend the overcoming experience through the vision of professional and amateur athletes under a phenomenological perspective. The interviews and analysis done with Jiu Jitsu athletes helped to understand this phenomenon. The overcoming was associated to a positive experience that provided gains even beyond the sporting context, and having the limit as its essential feature the overcoming experience gives value to the sports practicing itself. The athlete, who is challenged, links up, this way, with existential aspects from life studied by the phenomenological Psychology.
\end{abstract}

Keywords: Overcoming. Psychology. Phenomenology.

\footnotetext{
${ }^{1}$ Bacharel em Psicologia - UNIFAAT. Psicoterapeuta em Bragança Paulista - SP.

${ }_{2}^{2}$ Psicóloga pela PUC Campinas, Mestre em Psicologia Clínica pela PUC Campinas e Doutora em Educação pela Unicamp.
} 


\section{Introdução}

O interesse pela presente pesquisa, realizada ao longo do ano de 2016, surgiu a partir de um estágio de observação realizado em uma academia de artes marciais no interior de São Paulo, atividade que proporcionou verificar a disciplina e o empenho de um grupo de atletas nos treinos intensos dentro da academia. Neste processo também foi possível compreender, por meio de uma visão fenomenológica, como ocorre a experiência da superação em atletas das artes marciais, utilizando para tanto os principais conceitos da Psicologia fenomenológica e explorando aspectos da Psicologia do esporte e da superação.

Atualmente, a Psicologia quebra paradigmas relacionados à sua contribuição em diferentes contextos (RUBIO, 2006) e este estudo surge como uma oportunidade para compreender melhor a sua inserção no meio esportivo. O esporte emerge como importante ferramenta nos meios de convívio social, facilitando a inserção das pessoas em grupos que atribuem valor e sentido às suas vidas (CASCO, 2018). Compreender como o esporte se torna significativo para seus praticantes pode contribuir para a prática de profissionais da área e atletas e para a compreensão de suas vivências subjetivas (FRASCARELI, 2008).

É possível relacionar a origem da Psicologia do esporte à Grécia Antiga (considerada o berço dos jogos Olímpicos), quando filósofos como Aristóteles e Platão pensavam sobre a função perceptual do movimento associada aos conceitos de corpo e alma, já que a alma seria o princípio que moveria o homem para a ação (FIORESE VIEIRA e Cols. 2010). O precursor da Psicologia do esporte, no entanto, foi Norman Triplett (1861-1931), um psicólogo Norte Americano que em 1898 pesquisou se os ciclistas pedalavam mais rápido sozinhos ou acompanhados (STRUBE, 2005; UNESCO, 2013).

No Brasil, a Psicologia do esporte teve seu início em 1950 com o psicólogo João Carvalhaes, que realizava a seleção de candidatos na Escola de Árbitros da Federação Paulista de Futebol utilizando métodos psicotécnicos e o acompanhamento psicológico dos jogadores do São Paulo Futebol Clube (UNESCO, 2013). Para Casal (2007), a Psicologia do esporte ainda é uma subárea emergente do país, e isso se deve (dentre outros aspectos) ao fato de o Brasil investir pouco no esporte nacional, e por consequência, as áreas de estudo e atuação relacionadas ao esporte são pouco estimuladas. Também raramente a Psicologia do esporte constitui uma disciplina na grade curricular dos cursos de Psicologia, enquanto nos cursos de Educação Física é uma disciplina obrigatória (RUBIO, 1999). 
A Psicologia do esporte no Brasil, no entanto, conta com o maior número de contribuições (congressos, pesquisas, publicações) e laboratórios na América Latina (FIORESE VIEIRA e Cols. 2010). Em 2006 foi criada a Associação Brasileira de Psicologia do Esporte (ABRAPESP), que busca estimular a promoção de conhecimento acerca da Psicologia do Esporte no Brasil promovendo encontros, projetos e discussões sobre a pesquisa e a prática dos profissionais da área (ABRAPESP, 2015).

Apesar das contribuições da Psicologia no mundo esportivo, Frascareli (2008) aponta que a Psicologia do esporte está mais relacionada com o desenvolvimento de técnicas que visam a melhorar o desempenho dos atletas atuando a serviço de interesses políticos ou econômicos do que a serviço do próprio atleta, e atenta sobre a importância de realizar intervenções significativas para o atleta enquanto sujeito.

A Psicologia do esporte realiza o estudo e as intervenções nos contextos de atividade física padronizada com esportistas amadores ou profissionais, uma vez que a prática esportiva emerge em um contexto de regras e treinamento de atividade física institucionalizada e fiscalizada por técnicos e especialistas, ou seja: uma prática inserida dentro de um contexto padronizado (BARBANTI, 2006).

Neste âmbito existem os atletas que atuam em níveis profissional e amador. $\mathrm{O}$ atleta amador realiza a prática de esporte sem fins lucrativos ou sem o intuito de se envolver profissionalmente com uma carreira esportiva. É possível participar de competições e campeonatos enquanto um atleta amador, assim como dedicar-se fielmente aos treinos padronizados de uma modalidade, entretanto, o que diferencia o atleta amador do profissional é ter o esporte enquanto principal atividade (MARQUES e SAMULSKI, 2009; RUBIO, 2011).

É muito comum, no cenário esportivo, tanto amador como profissional, deparar-se com a superação de limites. Histórias de superação são encontradas na prática esportiva e atuam como motivação para que muitos atletas coloquem em movimento os ideais olímpicos de superação dos próprios limites. Silva e Rubio (2003, p.70) citam que: "Mesmo diante das muitas transformações ocorridas ao longo do último século no ambiente esportivo, o espírito de superação ainda perdura como um dos valores morais mais preciosos do esporte".

Entender como ocorre a experiência da superação no esporte envolve, portanto, compreender as dimensões da palavra "limite". Condição indispensável para que a superação se revele, o limite tem duas possíveis interpretações: 
A primeira: os limites no sentido da restrição de liberdade, que correspondem aos deveres morais. A segunda: os limites no sentido da superação, que correspondem aos ideais, ao auto-aperfeiçoamento, às virtudes (LA TAILLE, 2002, p.23).

Segundo La Taille (2002), essas duas interpretações sobre o limite são indissociáveis. Para falar sobre essa relação, La Taille explica, por meio da filosofia, que o limite como restrição de liberdade está associado a uma concepção moral (e ao dever), e enquanto superação o limite está associado à virtude. A moral pressupõe como dever a promoção do bem-estar dos homens, e para que isso seja possível, o esforço e a busca pelo aperfeiçoamento de si mesmo se fazem necessários (KANT, 1985 apud. LA TAILLE, 2002).

A superação no esporte também faz parte da história da Grécia Antiga. Segundo Rubio (2006), esta superação era denominada "agonística" e era caracterizada pela perseverança na construção da melhor forma atlética. As competições eram uma forma de vencer os próprios limites e experimentar uma aproximação divina.

Partindo dessas considerações, buscou-se, para o desenvolvimento deste trabalho, explorar a superação enquanto um fenômeno. A Psicologia fenomenológica se encarrega de compreender as relações estabelecidas entre o ser e o mundo por intermédio de suas experiências. Por esse motivo optou-se por uma pesquisa de viés fenomenológico para entender a experiência da superação.

Edmund Husserl, filósofo e matemático, fundador da fenomenologia, a definiu como um método de pensamento que busca voltar ao ponto inicial para a compreensão dos fenômenos, por meio da suspensão de julgamentos, crenças e preconceitos (redução fenomenológica que nos permite compreender as relações entre o homem e o mundo) e por meio da busca pela essência dos fenômenos, que é o caráter estrutural e invariante da experiência humana (redução eidética) - as duas reduções resumem o método fenomenológico (HOLANDA, 1997; SILVA, 2009).

Segundo Barbosa (2014) a aproximação da essência do fenômeno por meio da redução eidética nos permite perceber aspectos dos fenômenos que, sendo invariantes, são percebidos por mais de um sujeito, e não apenas individualmente. A essência pode ser compreendida como uma ideia coletiva, em comum entre sujeitos que se relacionam com determinado fenômeno.

Compreender como o fenômeno se mostra a cada sujeito, a partir das reduções fenomenológica e eidética, constitui para a fenomenologia uma preocupação maior do que 
descobrir as causas de um fenômeno (GOTO, 2008). A preocupação da fenomenologia com a experiência humana envolve o reconhecimento do papel do homem enquanto sujeito ativo na construção de conhecimento e na compreensão dos fenômenos; um ser que não é passivo diante do mundo em que vive, mas que atribui sentido e é capaz de realizar escolhas.

Segundo Goto (2008), Husserl defendeu que a tarefa do psicólogo seria desenvolver a Psicologia como uma via de acesso à subjetividade, pois só então teríamos a nosso alcance uma descrição psicológica dos fenômenos da consciência. Dessa maneira, ele deu nome a uma Psicologia que deveria considerar a fenomenologia: a Psicologia Fenomenológica, pensada a partir da filosofia. A relação com o mundo e com os outros nos permite adquirir experiências subjetivas, que nos despertam emoções e sentimentos e permanecem em nossa história, contribuindo para a formação de nossos pontos de vista e atribuições de sentido à nossa própria existência.

Neste sentido, a fenomenologia é diferente da ciência positivista, pois não pretende classificar ou quantificar fenômenos, e sim compreender as relações entre homem e mundo e a subjetividade envolvida nestas relações e nas experiências proporcionadas por elas (SILVA, 2009; FORGHIERI, 2011). Enquanto a ciência positivista desconsidera o sujeito e suas vivências, a fenomenologia tenta compreender as relações entre sujeito e mundo, envolvendo o homem e sua subjetividade em suas contribuições.

A partir do respaldo teórico apresentado ao longo desta introdução, buscou-se compreender a experiência da superação de limites no meio esportivo à luz da Psicologia fenomenológica.

\section{Método e procedimentos}

A pesquisa fenomenológica está relacionada à pesquisa empírica qualitativa na medida em que busca compreender percepções, atitudes e motivações acerca dos temas pesquisados. Segundo Garnica (1997) a pesquisa qualitativa permite descortinar o que a ciência clássica classifica como impreciso e dinâmico a fim de compreender aspectos do meio em que o homem vive e constrói não passíveis de serem medidos.

Para Creswell (2007), a pesquisa fenomenológica tem por objetivo compreender o sentido que alguns indivíduos atribuem para suas experiências em relação a um fenômeno, descrevendo o que os participantes apresentam em comum. Essa descrição consiste em uma 
tentativa de entender os elementos invariantes do fenômeno e como ele é vivenciado pelos participantes. Neste sentido, a essência do fenômeno é acessada, na pesquisa fenomenológica, quando se descrevem elementos comuns e invariantes nas experiências vividas pelos sujeitos da pesquisa (CRESWELL, 2007 e HOLANDA, 2006)

Seguindo as orientações de uma pesquisa fenomenológica foram entrevistados, no ano de 2016, três atletas adultos que praticavam artes marciais em uma academia da cidade de Bragança Paulista - SP, sendo dois participantes do sexo masculino e uma participante do sexo feminino. Entre os participantes, dois eram atletas amadores (um do sexo masculino e uma do sexo feminino) e um era atleta profissional. A faixa etária dos participantes era de 18 a 35 anos.

Todo o procedimento foi autorizado pelo Comitê de Ética da instituição de ensino superior UNIFAAT, e antes que as entrevistas fossem executadas, os participantes assinaram um Termo de Consentimento Informado. A fim de não identificar o nome dos participantes no texto da pesquisa, foram utilizadas apenas as iniciais dos nomes, gênero e idade correspondentes a cada participante.

Os procedimentos do estudo envolveram dois momentos: uma entrevista narrativa individual com uma pergunta disparadora e uma entrevista devolutiva. Tanto as entrevistas narrativas como as entrevistas devolutivas foram realizadas individualmente, e o local escolhido pelos participantes foi o tatame da academia após a realização das aulas.

A entrevista narrativa é um método de coleta de dados não estruturado desenvolvido por Fritz Schültze em 1970, sociólogo alemão da época pós Segunda-Guerra Mundial, nascido em 1944, que contribuiu para o desenvolvimento de métodos de pesquisa qualitativos significativos para o contexto científico (MUYLAERT e Cols. 2014; WELLER, ZARDO, 2013; KÖTTIG, VÖLTER, 2014).

Esse método é caracterizado pela elaboração final de uma história com trajetória sequencial a partir do relato do entrevistado a respeito de suas experiências (MUYLAERT e Cols. 2014). Neste sentido, a entrevista narrativa constitui uma modalidade de coleta de dados que favorece o acesso à experiência vivida pelo entrevistado, e por este motivo adequa-se à proposta de uma entrevista fenomenológica.

Schültze (2011, citado por WELLER, ZARDO, 2013) sugere três passos para a elaboração de uma coleta de dados a partir de entrevista narrativa: 1) pergunta narrativa ou questão disparadora: nesta etapa, enquanto pesquisadora, permiti que o entrevistado desse o 
seu depoimento sem interrupções; 2) exploração de aspectos resumidos do depoimento do entrevistado: nesta fase da coleta de dados, procurei realizar perguntas e intervenções buscando aprofundar o sentido da experiência resgatada pelo entrevistado; 3) solicitação de uma explicação subjetiva de elementos da trajetória que não ficaram claros ou que foram repetidos no depoimento do entrevistado: aqui pude, por exemplo, perguntar ao entrevistado os motivos de repetir muito a palavra força (para tentar compreender o que ele dizia eu observava: "Você falou algumas vezes sobre força, poderia me explicar que tipo de força é essa? O que você entende como força?" (sic.).

Segundo Köttig e Völter (2014), é importante que a questão disparadora convide o entrevistado a resgatar, em meio às suas experiências de vida, o tema proposto pelo pesquisador. A partir destas recomendações realizei um convite aos entrevistados, dizendo: “Gostaria que você (colaborador) me contasse um pouco sobre suas experiências de superação como atleta das artes marciais".

O material foi organizado e elaborado em forma de história em primeira pessoa, chamada de narrativa, que apresentei aos participantes na entrevista devolutiva, para que apontassem possíveis modificações. Amatuzzi (2007) destaca a importância da entrevista devolutiva como uma forma para evitar que o real sentido da experiência do sujeito seja comprometido no processo de registro em forma de narrativa realizado pelo pesquisador.

A análise das narrativas utilizada na pesquisa foi embasada na proposta de Amatuzzi (2007), que compreende a análise de dados na pesquisa fenomenológica em psicologia como uma sistematização das experiências coletadas pelo pesquisador. Desta forma, a pesquisa envolveu 4 momentos da análise de dados proposta por Amatuzzi (2007): 1) síntese particular de cada narrativa em que organizei as informações das narrativas individualmente, identificando e descrevendo os aspectos referentes ao objetivo da pesquisa; 2) sistematização das sínteses de todas as narrativas: em que busquei identificar variantes e invariantes narrativas, a fim de compreender aspectos essenciais da experiência de superação, chegando a uma síntese geral do vivido; 3) discussão de resultados: nesta fase da análise de dados foi realizado um diálogo da síntese geral com pesquisas e suportes teóricos a fim de aprofundar a compreensão da temática; 4) comunicação da pesquisa como forma de promoção de novos diálogos na comunidade científica ou outro público, que consiste na apresentação dos resultados da pesquisa para a comunidade acadêmica. 
A partir da elaboração das narrativas, das entrevistas devolutivas e das sínteses, foi possível ter contato com as experiências de superação de limites dos atletas participantes.

\section{Resultados e discussão}

Após a realização das entrevistas e a elaboração narrativa, obtiveram-se os resultados e discussões descritos neste capítulo, dividido em partes que descrevem os resultados obtidos com cada participante da pesquisa e o diálogo entre esses resultados e as referências bibliográficas utilizadas como subsídio teórico da pesquisa.

\section{B.P: 26 anos, sexo feminino (atleta amadora)}

Para B.P a superação estava muito relacionada à força física. A entrevistada explicou que a superação de limites físicos durante o treino, como o cansaço, levava à superação de limites psicológicos, que por sua vez possibilitavam o aprimoramento das técnicas das artes marciais e o ganho de força física. Para ela era possível sentir-se mais forte e confiante, tanto física como psicologicamente, ao perceber os limites sendo superados durante os treinos.

B.P iniciou a prática de Jiu Jitsu como uma forma de proteção pessoal, pois considera que como mulher se sente vulnerável em algumas situações. As aulas de Jiu Jitsu constituíam para ela uma forma de sentir-se mais forte e segura. A superação para B.P foi caracterizada como uma experiência concreta durante os treinos, e segundo a aluna, gera resultados positivos, fazendo-a sentir-se preparada para as situações do cotidiano e motivada a continuar investindo no esporte: "Tem aquela aula que você está cansada, ofegante, pensa que não vai aguentar mais, e você dá o melhor de si, conclui o treino e quando percebe superou o seu limite. A gente encontra forças para continuar o treino, porque aos poucos vai percebendo que o desempenho melhora." (sic.).

$\mathrm{Na}$ entrevista devolutiva a participante expressou sua satisfação com o material dizendo que se identificava com a narrativa e que nenhuma alteração era necessária.

Como evidencia a narrativa de B.P a experiência da superação é vivenciada pela atleta nos treinos, especificamente nos momentos de maior cansaço e esgotamento quando ela percebe seus limites físicos e psicológicos. A superação estava relacionada a um processo iniciado com a percepção de seus limites: o cansaço e o esgotamento físico, além do desânimo psicológico, que a fazia pensar que não era capaz de concluir o treino. O esforço diante das 
dificuldades a levava a realizar os treinos completos e perceber, aos poucos, que os exercícios e golpes ficavam mais simples.

A superação pôde ser associada, a partir do que B.P apresentou, ao esforço que é sentido diante do cansaço e da persistência. Os resultados desse esforço são o aprimoramento de técnicas, ganho de força e de autoconfiança tanto no meio esportivo como no contexto pessoal, e eram motivadores para que B.P continuasse entrando em contato com seus limites nos treinos. Assim, percebe-se a superação enquanto uma vivência de enfrentamento durante os treinos, em que a atleta se depara com seus limites e persiste apesar do cansaço.

A experiência também ganha um caráter motivador para a participante, já que ao superar seu esgotamento ela se sentia mais forte e capaz de lidar com os treinos e com possíveis situações ameaçadoras em outros contextos (situações às quais ela acredita estar sujeita em decorrência do seu gênero e da violência cotidiana).

\section{A.V: 28 anos, sexo masculino (atleta amador)}

A.V disse que, em sua opinião, a superação estava relacionada à disciplina e autorrespeito, e explicou que desde que havia iniciado os treinos de Jiu Jitsu percebeu melhoras nestes dois aspectos. O atleta explicou que seguir uma rotina regrada, por exemplo, se tornou uma tarefa mais fácil. Ele também destacou a importância dos treinos para sua vida fora dos tatames, dizendo que a prática do Jiu Jitsu o ajudava a superar limites em outras áreas: quando um problema pessoal ou uma situação ruim se apresentava em sua vida, o que o ajudava era se distanciar e olhar as coisas com mais clareza, e para ele os treinos ajudaram nesse aspecto.

A.V explicou que o atleta que pratica Jiu Jitsu se depara com golpes que o colocam em posições nas quais precisa se esforçar e pensar para sair sem se lesionar ou perder a luta. Neste momento da prática o atleta corre risco e se depara com limites que precisam ser superados - o descontrole psicológico, a sensação de agonia e o desespero. Para superar os limites defrontados durante a execução dos golpes, é necessário ser frio e tentar encarar a posição de modo calculista. Ele relatou que essa postura o ajuda a encarar os desafios cotidianos: "Quando eu estou diante de um problema, eu tento levar essa superação comigo, ficar mais calculista e tentar solucionar, da mesma forma como faço no tatame.” (sic.).

$\mathrm{Na}$ entrevista devolutiva o participante deixou claro que se identificava com a narrativa, gostara da experiência e não seria necessária qualquer alteração do material. 
A superação é vivenciada pelo participante principalmente na prática dos golpes. Segundo A.V os golpes de Jiu Jitsu colocam qualquer atleta em uma posição desconfortável, desafiadora e arriscada capaz de pressionar o praticante a desistir da luta ou esforçar-se para sair da posição. Para que a superação dessas dificuldades se concretize é necessário ter uma atitude de percepção dos próprios limites. Trata-se de um processo de identificar limites e pensar friamente nas possíveis falhas do golpe, encontrando uma saída para não se machucar ou perder a luta: uma habilidade que ele leva para além do contexto das artes marciais.

Vivenciar a superação nos tatames ajudou A.V a superar adversidades em sua vida pessoal. Diante de situações desafiadoras, o atleta, assim como nos treinos, adota um posicionamento calculista buscando resolver seus problemas e superar ocorrências capazes de colocá-lo diante de seus limites pessoais.

\section{F.S: 31 anos, sexo masculino (atleta profissional)}

F.S resgatou calmamente memórias de sua infância e de sua carreira para falar sobre sua experiência com a superação no esporte. Ele associou a experiência a uma ferramenta no mundo das artes marciais, que exige muita disciplina por parte do esportista devido aos intensos treinamentos que englobam concentração, respiração, força e persistência, e que neste contexto o atleta é levado ao encontro de limites físicos e psicológicos (tanto em situações de treino como em competições).

Em sua experiência profissional, F.S teve contato com atletas que superavam seus limites na medida em que mudavam seus hábitos para concluir os treinos. Ele explicou que, quando o atleta muda seus hábitos e adquire disciplina, passa a perceber melhoras no desempenho durante a prática do esporte e se sente motivado a continuar se dedicando às artes marciais e superando seus limites de uma forma cíclica, percebendo também melhoras na sua vida fora dos tatames.

O atleta, em sua infância, tinha um quadro de obesidade que prejudicava suas atividades. Se tivesse considerado as recomendações médicas, F.S não haveria se envolvido com nenhuma prática esportiva. Apesar das recomendações, F.S conheceu as artes marciais e se interessou pela prática. Durante as práticas, o atleta, ainda muito jovem, percebia seu ponto de esgotamento nos treinos e as dificuldades em meio ao seu esforço. Aos poucos ele percebeu que era possível superar estes limites através de uma dedicação intensa aos treinos e da disciplina que eles exigiam. 
Sendo assim o jovem atleta investiu em um conjunto de fatores que o ajudaram a superar seus limites, tanto dentro do esporte como fora dos tatames: aliou a alimentação regrada à frequência assídua das aulas e seu esforço físico, que muitas vezes o desafiaram. Dessa forma, F.S fez do esporte a sua profissão e seu estilo de vida. Para o atleta a superação é um fenômeno capaz de produzir mudanças e motivar a prática e a disciplina dentro do contexto esportivo, garantindo a melhora do desempenho do esportista.

$\mathrm{Na}$ entrevista devolutiva F.S disse ter se identificado com a narrativa redigida e que não seria necessária nenhuma alteração.

F.S associou a superação dentro dos tatames à quebra de preconceitos em relação ao esporte em si, à busca pela concentração e à persistência nas lutas. O próprio envolvimento dele com a prática de artes marciais começou a partir de uma transgressão: apesar das recomendações médicas o atleta iniciou nos treinos, superando assim os limites impostos pelo Outro. O interesse pelo esporte foi maior do que o medo das consequências de sua prática, que poderiam colocar em risco sua saúde. Resgatando sua história F.S evidencia que fazia mais sentido testar-se no esporte do que seguir os conselhos do médico.

Para ele a superação de limites permite aos esportistas perceberem avanços e ganhos na prática, de uma forma concreta, através da melhora do desempenho. Essa percepção, por sua vez, motiva o atleta a continuar dedicando-se à prática e a continuar superando novos limites.

A síntese geral obtida a partir da análise de cada narrativa permitiu constatar que a superação no esporte pode ser percebida em meio ao cansaço e aos desafios encontrados nos treinos, classificados pelos participantes como limites físicos e psicológicos; em meio à sensação de que o corpo não responderá às exigências da prática esportiva, ou que a mente cederá à desmotivação levando o atleta a crer que não será possível vencer a luta ou cumprir o treino, surge a persistência levando o atleta a adotar uma postura desafiadora diante de seus limites (a superação enquanto processo de reviravolta).

Em todos os casos a persistência e os limites foram pontuados como aspectos essenciais da superação - sem falar sobre esses dois fatores os atletas não conseguiriam falar sobre a superação. Como um círculo vicioso, a superação é capaz de motivar o esportista a desafiar novos limites, pois ela foi descrita como um processo que se inicia no confronto dos limites e na sensação inicial de desmotivação e ao final é associada ao sentimento de vitória 
(pois evoca ganhos ao atleta) e à melhora do desempenho esportivo (os limites, a superação e a motivação estabelecem uma dinâmica cíclica).

Os atletas citaram a superação como um fenômeno propulsor de mudanças em suas vidas pessoais (fora do contexto esportivo), tanto em relação à postura adotada diante de desafios como à mudança de hábitos fora dos tatames. Um dos fatores que se relaciona com tais mudanças são os resultados percebidos nos treinos, que levam o atleta a pensar que é capaz de superar limites em outros contextos (superação como experiência motivadora).

Embora todos os atletas tenham traçado um paralelo da superação no esporte com suas vidas fora do contexto esportivo, cada um fez isso a seu modo. Essa diferença em cada narrativa é o que caracterizou a subjetividade dos participantes e evidenciou diversas faces do fenômeno da superação, mostrando que ele é capaz de ser vivenciado em diferentes contextos e mesmo assim estar relacionado ao esporte (superação enquanto fenômeno subjetivo).

No campo da Psicologia do esporte o psicólogo buscará compreender a maneira como o atleta se relaciona com o esporte e com os demais fenômenos emergentes desta relação, e fará isso por meio das reduções fenomenológica e eidética, suspendendo valores e julgamentos para buscar aspectos invariantes da vivência do atleta (FRASCARELI, 2008). As reduções fenomenológica e eidética foram, portanto, facilitadoras no processo de compreensão das vivências esportivas.

No desenvolvimento deste trabalho foram identificados aspectos invariantes do fenômeno da superação (essências do fenômeno) a partir do conceito de redução eidética, pois mesmo diante das diferenças e particularidades de cada entrevista foi possível notar os aspectos que caracterizavam a experiência da superação no cotidiano dos participantes. Entre estes aspectos é possível citar o limite e a motivação que se sobressaíram nas narrativas, além da situação de reviravolta que esteve no sentido dos discursos de cada entrevistado.

A associação feita por F.S diante de suas memórias de infância relacionaram-se com uma concepção de limite enquanto restrição, que segundo La Taille (2002), está ligada às constituições morais que se apresentam ao sujeito. $\mathrm{O}$ autor faz uma consideração importante ao notar que "[...] a busca de superação de si (e não apenas no campo da moral) enfrenta dificuldades advindas de certos valores que são dominantes hoje em dia" (LA TAILLE, 2002, p.33).

A exemplo dessas dificuldades La Taille (2002, p.33) cita as atribuições de valores e pré-julgamentos feitos pelos homens e aos homens, geralmente associados a competitividade: 
“[...] o generoso é "deixado para trás", o humilde é "desprezado", o justo é “otário" e etc.". O próprio contexto esportivo pode ser carregado de estigmas estéticos que se tornam representações sociais dos atletas, como apontam Fernandes e Cols. (2015).

Em contrapartida, essas mesmas dificuldades podem ser motivadoras da superação. No caso de B.P, que iniciou nas aulas de Jiu Jitsu diante das situações sociais das quais se sentia sujeita (as violências urbanas e contra a mulher), podemos acompanhar um exemplo de ação que surge motivada por uma restrição.

Enfim, percebe-se que se os limites não se apresentam aos atletas não há situação a ser superada. O processo de superação se inicia diante de um evento que desafia o atleta. Este evento pode ser diferente para cada esportista ou mudar de acordo com a característica do esporte, mas se não levar o atleta de encontro aos seus limites, não haverá superação.

Conforme elucidam Silva e Porpino (2014, p.78)

[...] o atleta ultrapassa as fronteiras biológicas e normativas do esporte, cria e recria movimentos, vivencia situações de afetos e confrontos, de emoções e de paixões, atribuindo sempre novos sentidos por meio da estesia que o esporte revela ao atleta.

Ranieri e Barreira (2010, p.58) complementam essa compreensão descrevendo a superação como uma "[...] dinâmica singular de vivências que se empenham junto a um obstáculo até torná-lo rastro, deixá-lo para trás, antes tendo solicitado tensão crescente e desafiadora".

Em meio a esta dinâmica singular a motivação surgiu como uma vontade dos participantes em continuar se dedicando à prática esportiva, fosse diante das situações-limite, dentro do próprio treino, ou após a superação destas situações, quando o atleta passa a querer mudar seus hábitos para obter ganhos e superar novos limites.

Segundo Gazzaniga e Heatherton (2005) os estados motivacionais são energizantes, diretivos, estimulam a persistência e diferem em níveis de força. Isso significa que a motivação leva à ação, orientando os indivíduos a satisfazerem seus objetivos ou necessidades específicas, e por isso relaciona-se essencialmente com a superação.

Sobre a persistência dos estados motivacionais, Gazzaniga e Heatherton (2005) dizem que, enquanto uma necessidade não é satisfeita, o sujeito tende a realizar a ação até atingir seus objetivos. A força motivacional é investida de valor pelo sujeito, que realiza escolhas com base em seus objetivos e necessidades. Nas narrativas, essa força apareceu quando os 
atletas mostraram a escolha de continuar nos treinos em detrimento dos objetivos que pretendiam alcançar ou das sensações que gostariam de vivenciar.

$\mathrm{Na}$ Psicologia do esporte, o trabalho motivacional é capaz de otimizar o desempenho dos atletas, e podemos fazer a mesma interpretação do trabalho com a superação (SILVA, RUBIO; 2003). Antes de pensar em qualquer ação ou intervenção no contexto esportivo que considere estes fenômenos, precisamos, portanto, compreendê-los. Podemos fazer isso entrando em contato com a forma como esses fenômenos são vistos pelos esportistas.

As considerações dos atletas demonstraram que a motivação também está intrinsecamente envolvida com o caráter cíclico da superação. Na medida em que os limites vão sendo superados pelo esportista, novos limites surgem. Para que estes limites surjam novamente durante os treinos e sejam superados, o atleta precisa estar suficientemente motivado para participar do esporte, criando novas oportunidades de superação.

Em meio a esta característica cíclica da superação, o esporte consegue configurar-se enquanto uma contemplação do devir, do transcender e do existir, carregado de sentidos provindos da relação homem-mundo, como apontam Silva e Porpino (2014), e possibilita acompanhar o desenvolvimento das potencialidades do ser humano.

A temporalidade presente na superação como um processo indicou uma situação de reviravolta, que surge de uma situação em que o atleta se encontra fadigado e desestabilizado: a superação permite que o esportista conclua sua atividade e ainda consiga identificar ganhos provindos dessa conclusão. Para Ranieri e Barreira (2010), o processo envolvido na ação de superar-se está relacionado às sucessivas vivências que se dinamizam e chegam à totalidade da experiência da superação.

Segundo Merleau-Ponty (2006), não existe uma relação dicotômica entre mente e corpo. O filósofo fenomenólogo francês nos aponta que o corpo próprio é sempre percebido pelo sujeito, e isso significa que sua ausência é impensável, tão logo as experiências corpóreas nos acompanham a todo momento.

Se tratando de uma postura, a superação é também resultado de uma escolha. Os limites, que se apresentam como desafios, podem ou não ser superados, o que vai depender do atleta e da leitura que ele faz desse desafio. É essa escolha no processo de superação que estimula, segundo Ranieri e Barreira (2010, p.58), uma existencialidade esportiva, que descreve a superação como 
[...] uma das experiências centrais do fenômeno esportivo que motivam à prática $\mathrm{e}$ tem neste entrelaçamento existencial da objetividade esportiva com a subjetividade vivida a fonte que dá um significado singular ao esporte.

Merleau-Ponty (2006, p.281) sugere que "[...] retornemos então à sensação e observemo-la de tão perto que ela nos ensine a relação viva daquele que percebe seu corpo e seu mundo". Assim pude notar que os participantes levavam suas experiências externas para dentro do tatame. Essas experiências motivavam a prática esportiva, segundo os atletas, portanto, posso dizer que estavam envolvidas no processo de superação.

A estrutura geral do vivido que sintetizou os principais resultados obtidos a partir da pesquisa aponta que a superação foi associada pelos entrevistados a uma experiência positiva, gratificante e, portanto, motivadora (GAZZANIGA, HEATHERTON; 2005). Essa experiência é também discutida por Silva e Rubio (2003), que apontam o quanto os atletas almejam transcender os próprios limites desde a antiguidade, buscando assim uma experimentação que beira o divino.

Finalmente, é possível entender o quanto esse fenômeno atribui um valor central ao esporte, como apontam Ranieri e Barreira (2010), colocando o atleta diante do sentido de sua prática, lhe proporcionando a sensação de capacidade e a exploração de suas potencialidades.

\section{Considerações finais}

A presente pesquisa colaborou com a compreensão do fenômeno da superação e o quanto é necessário repensar a Psicologia do esporte. Neste sentido cabe destacar a existência de um número muito grande de artigos científicos que buscam justificar a prática esportiva com suas possíveis consequências e ganhos, ou adequar a prática do atleta ao rendimento esportivo.

A Psicologia do esporte deve se preocupar em como o atleta vivencia a prática esportiva em si e como ocorre sua interação com o mundo por meio do esporte, muito mais do que pensar nas consequências positivas e negativas da atividade física institucionalizada ou com aspectos meramente lucrativos deste meio. O diferencial da Psicologia fenomenológica é a compreensão das relações entre homem e mundo, que vão além da adequação do homem ao meio. É essa compreensão que permite intervir de forma ética e eficiente nos diversos contextos em que a Psicologia se insere e atuar de forma coerente. 
A superação está tão relacionada a uma postura do sujeito diante dos desafios como um processo, que se caracteriza em uma vivência capaz de motivar e desenvolver as potencialidades do atleta. No esporte esses desafios são transcritos em experiências corpóreas intensas que colocam o esportista diante de uma situação de reviravolta, caso seja sua escolha superar estes limites. Isso atenta para o papel do atleta como sujeito central diante da prática esportiva e mostra o quando ela pode estar relacionada a aspectos existenciais na vida do homem. Ignorando estes aspectos, dificilmente a Psicologia conseguiria se inserir no contexto esportivo, pelo menos fazendo aquilo que lhe é essencial: contribuindo para o autoconhecimento e a autonomia do homem neste contexto.

Os participantes mostraram o quanto a liberdade, a responsabilidade e a ação (condições existenciais) estão envolvidos na superação dos limites dentro do esporte: tarefa nada fácil considerando seu caráter desafiador envolvido até com aspectos sociais, mas sempre relacionada pelos entrevistados como positiva e gratificante.

\section{Referências}

ABRAPESP. Associação Brasileira de Psicologia do Esporte. 2015. Disponível em: http://www.abrapesp.org.br/sobre. Acesso em: 10 dez. 2019.

AMATUZZI, M.M. Pesquisa fenomenológica em psicologia. In: BRUNS, M. A. T; HOLANDA, A.F. (orgs.). Psicologia e pesquisa fenomenológica: reflexões e perspectivas. 2 ed.São Paulo: Alínea, 2007, p. 17-25.

BARBANTI Valdir. O que é o esporte? Revista Brasileira de Atividade Física e Saúde, Florianópolis, v.11, n.1, p.54-58. 2006. Disponível em: http://rbafs.org.br/RBAFS/article/view/833/84. Acesso em: 12 dez. 2019.

BARBOSA, R.B. A ideia Husserliana de fenomenologia. Inconfidentia - Revista Eletrônica de Filosofia, Mariana, v.2, n.2, p.22-40, jan./jul. 2014. Disponível em:

http://inconfidentia.famariana.edu.br/wp-content/uploads/2014/08/A-ideia-husserliana-defenomenologia.pdf. Acesso em: 18 dez. 2019.

CASAL, H. M. V. Fatos e reflexões sobre a história da Psicologia do Esporte. In: BRANDÃO, M. R. F; MACHADO, A. A. Coleção Psicologia do Esporte e do Exercício. São Paulo: Atheneu. 2007, p.1-29. v.1.

CASCO, R. Ideologia esportiva e formação do indivíduo: contribuições da teoria crítica do esporte. Psicologia USP, São Paulo, v.29, n.2, p.179-188, 2018. Disponível em: http://www.scielo.br/pdf/pusp/v29n2/1678-5177-pusp-29-02-179.pdf. Acesso em: 09 dez. 2019. 
CRESWELL, J.W. Qualitative Inquiry and Research Design: Choosing among five approaches. 2nd. Ed. Thousand Oaks, CA: SAGE Publications, 2007. 398p. Disponível em: http://www.stibamalang.com/uploadbank/pustaka/RM/QUALITATIVE\%20INQUIRY\%20ok .pdf. Acesso em: 12 dez. 2019.

FIORESE VIEIRA, L; VISSOCI, J.R.N; OLIVEIRA, L.P; LOPES VIEIRA, J.L. Psicologia do esporte: uma área emergente da psicologia. Psicologia em Estudo, Maringá, v.15, n.2, p.391-399, abr. /jun. 2010. http://www.scielo.br/pdf/pe/v15n2/a18v15n2. Acesso em: 17 dez. 2019.

FORGHIERI, Y. C. Psicologia Fenomenológica: Fundamentos, Método e Pesquisas. São Paulo: Cengage Learning, 2011.

FRASCARELI, L.S. Interfaces entre psicologia e esporte: sobre o sentido de ser atleta. 2008. Dissertação (Mestrado em Psicologia) - Universidade de São Paulo, São Paulo. 2008.

GARNICA, A.V.M. Algumas notas sobre pesquisa qualitativa e fenomenologia. Revista Interface, Botucatu, v.1, n.1, p.109-122, ago.1997. Disponível em: http://www.scielo.br/pdf/icse/v1n1/08.pdf. Acesso em: 12 dez. 2019.

GAZZANIGA, M.S; HEATHERTON, T.F. Motivação. In: GAZZANIGA, M.S; HEATHERTON, T.F. Ciência Psicológica: mente, cérebro e comportamento. Trad. VERONESE, M.A.V.V. Porto Alegre: Artmed. 2005.

GOTO, T.A. Introdução à Psicologia fenomenológica: a nova Psicologia de Edmund Husserl. São Paulo: Paulus, 2008.

HOLANDA, A. Fenomenologia, psicoterapia e psicologia humanista. Revista Estudos de Psicologia, Campinas, v.14, n.2, p.33-46, maio/ago.1997. Disponível em: http://www.scielo.br/pdf/estpsi/v14n2/04.pdf. Acesso em: 20 dez. 2019.

HOLANDA, A. Questões sobre pesquisa qualitativa e pesquisa fenomenológica. Revista Análise Psicológica, Lisboa, v.24, n. 3, p.363-372, jul. 2006. Disponível em: http://www.scielo.mec.pt/pdf/aps/v24n3/v24n3a10.pdf. Acesso em: 10 dez. 2019.

KÖTTIG, M; VÖLTER, B. “Isso, sim, é ser sociólogo!”: uma entrevista narrativa com Fritz Schültze sobre a história de sua obra na sociologia. Revista de Ciências Sociais Civitas, Porto Alegre, v.14, n. 2, p.204-226, maio/ago. 2014. Disponível em: http://revistaseletronicas.pucrs.br/ojs/index.php/civitas/article/view/17840/11470. Acesso em: 14 dez. 2019.

LA TAILLE, Y. Uma interpretação psicológica dos “Limites” do Domínio Moral: Os Sentidos da Restrição e da Superação. Revista Educar, Curitiba, n.19, p.23-37, 2002. Disponível em: http://www.scielo.br/pdf/er/n19/n19a03.pdf. Acesso em: 18 dez. 2019.

MARQUES, M.P; SAMULSKI, D.M. Análise da carreira esportiva de jovens atletas de futebol na transição da fase amadora para a profissional: escolaridade, iniciação, contexto sócio-familiar e planejamento da carreira. Revista Brasileira de Educação Física e Esporte, 
São Paulo, v.23, n.2, p.103-119, abr./jun. 2009. Disponível em: http://www.revistas.usp.br/rbefe/article/view/16714/18427. Acesso em: 12 dez. 2019.

MERLEAU-PONTY, M. Fenomenologia da percepção. 3 ed. Trad. MOURA, C.A.R. São Paulo: Martins Fontes. 2006.

MUYLAERT, C.J; SARUBBI JÚNIOR, V.S; GALLO, P.R; ROLLIM NETO, M.L; REIS, A.O.A. Entrevistas narrativas: um importante recurso em pesquisa qualitativa. Revista da Escola de Enfermagem da Universidade de São Paulo (USP), São Paulo, v.48, n.2, p.193199, dez. 2014. Disponível em: http://www.scielo.br/pdf/reeusp/v48nspe2/pt_0080-6234reeusp-48-nspe2-00184.pdf. Acesso em: 09 dez. 2019.

RANIERI, L.P; BARREIRA, C.R.A. A superação esportiva vivenciada por atletas com deficiência visual: análise fenomenológica. Revista Brasileira de Psicologia do Esporte, São Paulo, v.3, n.2, p.46-60. 2010. Disponível em:

http://pepsic.bvsalud.org/pdf/rbpe/v3n2/v3n2a05.pdf. Acesso em: 18 dez. 2019.

RUBIO, K. A Psicologia do Esporte: Histórico e Áreas de Atuação e Pesquisa. Revista Psicologia, ciência e profissão, Brasília, v.19, n3, p.60-69. 1999. Disponível em: http://www.scielo.br/pdf/pcp/v19n3/07.pdf. Acesso em: 12 dez. 2019.

. O Imaginário da Derrota no Esporte Contemporâneo. Revista Psicologia e Sociedade, [on line], v.18, n.1, p.86-91. 2006. Disponível em: http://www.scielo.br/pdf/psoc/v18n1/a12v18n1.pdf. Acesso em: 14 dez. 2019.

A Dinâmica do Esporte Olímpico do Século XIX ao XXI. Revista Brasileira de Educação Física e Esporte, São Paulo, v.25, n.esp., p.83-90. 2011. Disponível em: http://www.scielo.br/pdf/rbefe/v25nspe/09.pdf. Acesso em: 18 dez. 2019.

SILVA, F.A.N. Fenomenologia e Psicologia: Uma Relação Epistemológica. Revista Psicologia em foco, Aracaju, v.2, n.1, p.139 - 142. 2009. Disponível em: http://pepsic.bvsalud.org/pdf/rag/v15n2/v15n2a02.pdf. Acesso em: 17 dez. 2019.

SILVA, L.M.F; PORPINO, K.O. Esporte como experiência estética e educativa: uma abordagem fenomenológica. HOLOS [on line], v.5, p.64-80, nov. 2014. Disponível em: https://core.ac.uk/download/pdf/71373021.pdf. Acesso em: 18 dez. 2019.

SILVA, M.L; RUBIO, K. Superação no Esporte: Limites Individuais ou Sociais? Revista Portuguesa de Ciências do Desporto [on line], v.3, n.3, p.69-76, 2003. Disponível em: https://rpcd.fade.up.pt/_arquivo/artigos_soltos/vol.3_nr.3/LSilva.pdf. Acesso em: $20 \mathrm{dez}$. 2019.

STRUBE, M.J. What did Triplett really find? A contemporary analysis of the first experiment in social psychology. The American Journal of Psychology, Illinois, v.118, n.2, p.271-286, 2005. Disponível em: https://www.ncbi.nlm.nih.gov/pubmed/15989124. Acesso em: 12 dez. 2019. 
UNESCO. Psicologia do Esporte: cadernos de referência do esporte, n.6. Brasília, 2013. Disponível em: https://unesdoc.unesco.org/ark:/48223/pf0000224991. Acesso em: 19 dez. 2019.

WELLER, W; ZARDO, S.P. Entrevista narrativa com especialistas: Aportes metodológicos e exemplificação. Revista da Faculdade de Educação do Estado da Bahia (FAEEBA) Educação e contemporaneidade, Salvador, v.22, n. 40, p.131-143, 2013. Disponível em: https://www.revistas.uneb.br/index.php/faeeba/article/view/757/530. Acesso em: 20 dez. 2019. 